\title{
Can I provide care to patients outside of work?
}

\section{Abi Rimmer speaks to three experts about whether it's safe to provide care to patients outside of a medical environment}

\section{Abi Rimmer}

The BMJ

\section{Help in an emergency}

Sissy Frank, medicolegal adviser at the Medical Defence Union, says, "Doctors often come forward to help in off duty emergencies. While there isn't a legal obligation to do so, the GMC states that 'you must offer help if emergencies arise in clinical settings or in the community. ${ }^{1}$ Before giving medical support, doctors must take into account their own safety, their competence, and the availability of other options, for example if there are more qualified people are on the scene.

"Where possible, a doctor helping in an emergency should also make a detailed record of the incident and their involvement, get consent from the patient, and explain their actions and treatment to the patient. The doctor should also, if possible, have a witness present-with the patient's consent where appropriate-particularly if they intend to conduct a physical examination.

"Retired doctors or medical students can also offer assistance in an emergency and the GMC advises that not having a licence shouldn't stop doctors from helping. Non-licensed doctors must, however, be clear about their GMC status. It is a criminal offence to inaccurately present yourself as being registered."

\section{Reassure friends and family}

Julie-Ann Maney, from the Royal College of Paediatrics and Child Health, says, "I'm easy going when it comes to giving advice to friends and family. I want to help everybody, particularly when it comes to children.

"I get asked all the time for medical advice. I get sent pictures with a message asking, 'Would you be worried about this?' You can't just ignore it, especially if you want to continue to have a relationship with the person who's sent it. You're also giving reassurance, which as a friend or relative you want to do. I always try and help when I can.

"I usually do a telephone consultation but these can be difficult as you can't see the child, so I often suggest bringing them round or I'll go to them. My sister will FaceTime me which is easier.

"Things can change so quickly with children. One minute they have a cold and next they could be in intensive care. There's a fine line to tread. Most of the time they come to you with straightforward problems, but there can be times where it's tough. I've had my niece arrive at the emergency department where I work, for example. It can cause great anxiety and you worry whether you made the right call. In these circumstances I ask a colleague to treat them instead.

"When I had my second child I attended a postnatal support group. Everyone asks what you do for a living. I would always try and change the subject or say I work in a hospital. On this occasion, there was another doctor in the room who knew what I did and subsequently broadcast it. Within 20 minutes someone openly asked me what I thought was wrong with their son's penis."

\section{Volunteering overseas}

Ewen Ross, medicolegal adviser at Medical Protection, says, "If you want to volunteer for a humanitarian disaster relief programme or give clinical care to a party travelling overseas, do your research. Look into the health matters specific to that region or activity, the country you're going to, and whether the Foreign and Commonwealth Office has issued any travel warnings.

"Working in remote areas without immediate support may push you to make challenging decisions in isolation, compared with working for a larger charity with a central base that you can rely on for help and advice. This may mean having to find a way to contact telemedicine clinics in other parts of the country.

"It's crucial to check that you have the necessary level of knowledge, training, experience, supervision, and appropriate indemnity in place before travelling. Try and clarify the extent to which the non-governmental organisation or charity will provide indemnity for you. Bear in mind that while their indemnity may meet a claim arising from the work, it may not extend to assistance in relation to other matters, such as a complaint to the regulator.

"Being involved in humanitarian work abroad or 'expedition medicine' as a doctor can be hugely rewarding. There are, however, different levels of medicolegal risk associated with these types of work and it's recommended that you contact your medical defence organisation in advance to ensure you have adequate indemnity."

General Medical Council. Good medical practice: domain 2: safety and quality: 26 . www. gmc-uk.org/ethical-guidance/ethical-guidance-for-doctors/good-medical-practice/domain2--safety-and-quality\#paragraph-24.

Published by the BMJ Publishing Group Limited. For permission to use (where not already granted under a licence) please go to http://group.bmj.com/group/rights-licensing/ permissions 
